\title{
VERSITA
}

\section{BIOTOPE MAPPING OF EXTENSIVE/INTENSIVE GRASSLAND SUPPORTED BY REMOTE SENSING AND MOBILE GIS IN EASTERN STYRIA (AUSTRIA)}

\author{
WOLFGANG SULZER ${ }^{1 *}$, JOSEF GSPURNING ${ }^{1}$, MARTIN MAGNES², RICHARD PINK, \\ MARC MUICK ${ }^{1}$, PHILIPP SENGL ${ }^{3}$ \\ ${ }^{1}$ Institute for Geography and Regional Sciences, University of Graz, A-8010 Graz, Heinrichstrasse 36, Austria; \\ e-mail: wolfgang.sulzer@uni-graz.at \\ ${ }^{2}$ Institute of Plant Sciences, University of Graz, Schubertstrasse 51, A-8010 Graz, Austria \\ ${ }^{3}$ Civil Engineering Bureau Kofler (Ziviltechnikkanzlei Kofler), Traföß 20, A-8132 Pernegg, Austria \\ ${ }^{*}$ Author for correspondence
}

\begin{abstract}
Sulzer W., Gspurning J., Magnes M., Pink R., Muick M., Sengl P.: Biotope mapping of extensive/ intensive grassland supported by remote sensing and mobile GIS in Eastern Styria (Austria). Ekológia (Bratislava), Vol. 32, No. 4, p. 335-344, 2013.

The paper presents a case study for the application of remote sensing data (ASTER, LANDSAT and RGB orthophotographs) and GIS and methods in the context of biotope/grassland mapping/ monitoring in the Province of Styria (Austria). The range of the applied case study covers the detection of extensive/intensive grassland by techniques of multi-temporal satellite and airborne classification for grassland detection. The methodologies of three topics are discussed in this paper: special intensive used grassland detection, the preparation of a field map, with pre-processed land use polygons, and the description of a conceptual approach for a mobile client/server GIS grassland management and monitoring support system. Although from the legal (Government of Styria) point of view these methodologies cannot be used for the specific biotope mapping purposes, the verified results are showing valuable additional information for the intensive mapping activity during the fieldwork and postprocessing.
\end{abstract}

Key words: biotope mapping, grassland, remote sensing, GIS, Styria.

\section{Background and objectives}

The increasing urbanization, human population growth and extensive use of agricultural land during recent decades have resulted in significant loss of habitats and biotopes in the rural landscapes. The drastic change is usually accompanied by many environmental problems, such as a reduction of green spaces and deterioration of the ecosystem.

Reduced financial resources have increased the need for innovative techniques for habitat mapping and updating the existing spatial databases (Bock, 2003). Instead of land-wide intensive field mapping and conventional visual interpretations of aerial photographs for biotope and grassland mapping, satellite data and integrated mobile GIS approaches prove to be powerful tools for increasing the efficiency of these activities. 
The application of remotely sensed data for nature conservation monitoring has been limited because until recently there was a mismatch between the spatial and thematic resolution of image data and the user and legal requirements for detailed maps and biotope monitoring. In the recent past, most of the operational land cover or habitat mapping applications relied either on visual interpretation of satellite images (e.g. Corine Land Cover), aerial photograph interpretation (e.g. the biotope and land use mapping) or field surveys (Natura, 2000) (Bock et al., 2005; Weiers et al., 2004). Remote sensing and GIS technologies are being increasingly used as tools to assist in grassland inventory and integration of data and as a mechanism for analysis, modelling and forecasting.

One of the first histories of remote sensing for grassland investigation is found in Poulton et al. (1985), who describe the development of remote sensing as a science in the mid-to-late 1960s. The launch of LANDSAT in 1972 extended remote sensing beyond air photo interpretation into the realm of digital analysis of multi-spectral and multi-temporal data. With highresolution sensors (satellites and airborne), the user community faces new opportunities in the automated analysis of image data. Object-based classification tools support the analyses and valorisation of high-resolution image content. Ehlers (2000) and Ehlers et al. (2003) claimed that consequently, new intelligent techniques will have to be developed that make use of GIS integration, multi-sensor approaches and context-based interpretation schemes. With this approach, land cover classification can be applied with RGB airborne data, too.

Grassland (meadows and pastures) is a land cover in the area of conflict between agriculture and conservation, where intensification of land use is a major threat to grassland biodiversity. Grassland use intensity is a key factor for the conservation value of grassland, and detailed spatial data on grassland use intensity is needed to improve strategies for biodiversity conservation (Franke et al. 2012). The authors also give short overview of the latest remote sensing studies for biodiversity, habitat monitoring and for issues of conservation. In the context of grass- and range-land monitoring, different remote sensing approaches have been developed for the characterization of grassland type and vegetation change, the mapping of pasture and grassland productivity and the derivation of biophysical properties such as biomass or grass cover. However, spatially explicit data on the intensity of grassland use can provide vital information for various applications such as biodiversity conservation, monitoring land-use intensification in areas with high conservation value as well as for refined inventories of greenhouse gas emissions (Franke et al., 2012).

In this paper, three topics (workflows) were selected to proof the possibilities of the integration of satellite images, special image processing tools for orthophotograph delineation and mobile GIS application design. The results of this work should support the intensive fieldwork for the biotope monitoring mapping in several districts in Eastern Styria. In this context, there is a need to explore how and with what quality satellite data can be used for the inquiry and monitoring of intensively and extensively used grassland.

(1) The analyses of multi-temporal satellite images (ASTER and LANDSAT) can provide information about the level of greening/maturity (from March to July) of the grassland. By including an additional rule set (height, slope angle, shape of field, unsuitable land-use categories like agricultural land, settlements, streets, water bodies, etc.) it is possible to exclude intensively used grassland by means of satellite image analyses. The selection of an appropri- 
ate sensor (geometric, spectral and temporal resolution), data pre-processing (geometric and spectral enhancement), the setup of a rule set, the classification of the intensive grassland excluding mask, and finally the evaluation process (field check) will be discussed in this paper.

(2) Conventional digital RGB orthophotographs can be hardly classified by means of image processing. Special image processing tools (object based classification) can provide landuse polygons at different levels of details even in spectral low-resolution images. These basic polygons can support and speed up the visual land-use mapping and can assist the fieldwork too.

(3) In addition to the methods already mentioned, industrial standard GIS-technology is used to integrate existing and future information layers within one consistent data container. The underlying database model is designed to meet the information needs of administrative instances as well as to implement the analytical tasks formulized by plant scientists and geo-specialists (possible fields of application: error propagation, time series analyses, pattern analyses, etc.); other advantages of this geodatabase-driven approach are good scalability and the high portability of the developed desktop system to mobile mapping devices which provide a user-friendly data acquisition environment.

\section{Objectives of the biotope mapping project in Styria}

In the year 2009, the civil engineering bureau Kofler was entrusted by the Styrian government to achieve a biotope mapping in the districts Weiz, Fürstenfeld, Hartberg and Feldbach. The intent was to map selected habitats in the whole Styrian territory until the year 2013 as groundwork for future landscape and nature protection planning. From the perspective of nature conservation, the focus of the mapping project is on extensive grassland (meadows and pastures), hedges, woody areas smaller than 1 ha and riparian woodlands.

Arable land (as known from the cadastral land register), building land and circulation areas and areas above $1500 \mathrm{~m}$ sea level were excluded in advance. The pure mapping area for the 2009 project was calculated with $626,11 \mathrm{~km}^{2}$ in a total area of about $3000 \mathrm{~km}^{2}$ and additionally more than $5000 \mathrm{~km}$ run length of flowing waters. The determination of the biotope types was carried out by using the 'Biotoptypenkatalalog der Steiermark' (Amt der Steiermärkischen Landesregierung, 2008).

An example mapping achieved by the applicant in the previous years showed that the assignment of the biotope-type borders in analogue orthophotographs in field and later digitalization was very time-consuming and error-prone. Owing to the fact that differently managed farmland can be easily confined on suitable orthophotographs (taken between May and July), the biotope borders were drawn in advance by use of ARCGIS in orthophotographs of the mapping area and the polygons were numbered explicit. These maps were handed to the fieldworkers. The fieldworkers had to fill in a data entry form a geographical description (assignment of the biotope-type respectively a biotope-type complex, the type of management, the structure of the biotope, adverse effects and the identifiable plant species) of each outlined polygon. For a clear assignation of the biotope types even through more than 30 different fieldworkers, a key on a floristical base was established and sampled in the beginning of the fieldwork period. In deep-level areas particularly, there was a great percentage 
of intensively managed grassland expected. The intensively managed and species-poor plots had to be only assigned but not described by the fieldworkers.

\section{Study area}

The investigation area covers the south-eastern part of the Province of Styria (Fig. 1). In this region, four districts (Weiz, Fürstenfeld, Feldbach and Hartberg) were selected for the biotope mapping activity. The region has an area of about $3024 \mathrm{~km}^{2}$ (effective mapping area is about $600 \mathrm{~km}^{2}$ ) and is characterized by two distinct rural landscapes types aligned from Eastern Alps in the north and a hilly area the south-east. The Eastern Alps are characterized by forest (Spruce, broadleaf trees) and mainly pasture grassland. The main part in between is dominated by a tertiary hilly area (Hügelland) with tertiary and quaternary deposits.

The different landscape characteristics have clearly influenced the land-use pattern. In the hilly area, broadleaf forest and cereal cropping on relatively large parcels are predominant. Cereal and maize cropping is concentrated mainly on the valley floors and gentle lower slopes.

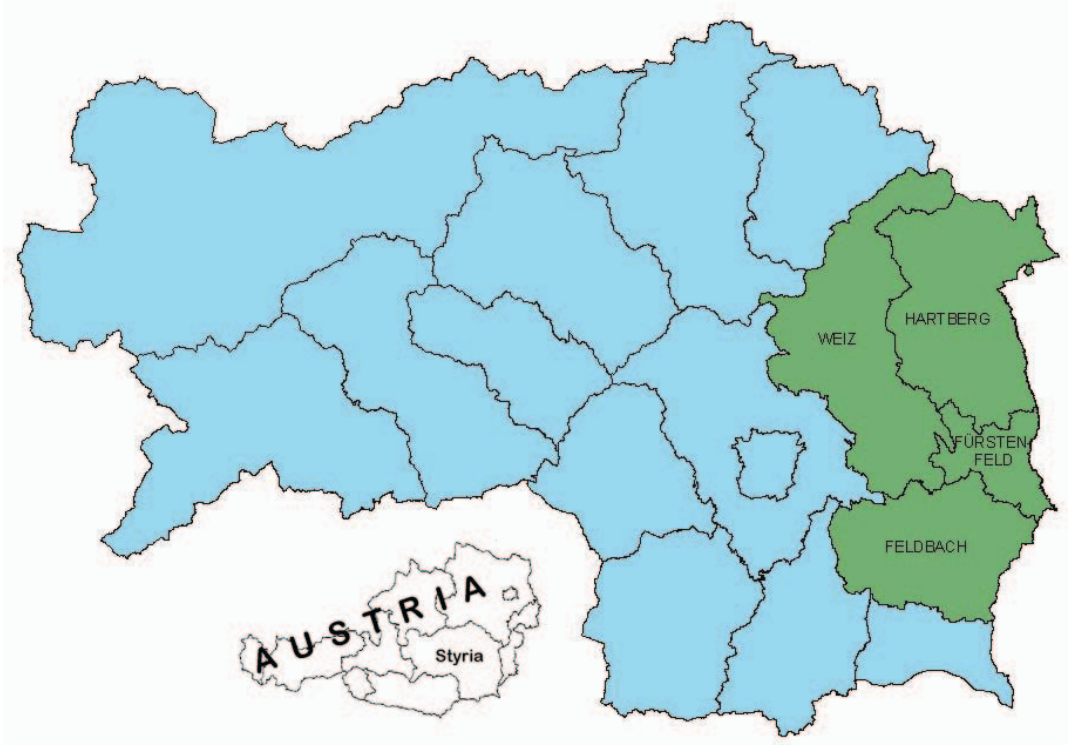

Fig. 1. Investigation area in Styria.

\section{Data basis}

The main data sources and their processing history are outlined in the following.

Remote sensing data: With regard to data availability, cost effectiveness, spectral, spatial and temporal resolution (15, 30, $90 \mathrm{~m}$ ) LANDSAT Thematic Mapper (TM) and ASTER data sets and orthophotographs are used for this study. These data sets fulfil the requirements of the methodology. With respect to the cloudlessness, coverage of the whole investigation area, seasonality and time intervals (multi-temporal aspects of greening and multi-cutting of the grassland) the following data sets were chosen (Fig. 2).

GIS data: The data sets were provided by the biotope mapping agency and the Government of Styria (GIS Steiermark). The main goal of the used layers is to exclude areas which are not potential extensive grassland biotopes (Fig. 2). 
Remote sensing data sets

- $\quad$ ASTER 2008: April, May, June, August and September

- LANDSAT 2008 April, August and October

- Airborne RGB Orthophotographs from the whole investigation area with a resolution of $25 \mathrm{~cm}$

\section{GIS data sets}

- DEM: Resolution of $10 \mathrm{~m}$

- Administrative borders

- $\quad$ Excluding layer data set in SHAPE format

- Forest

- Settlements

Streets

Rivers

Fig. 2. Basic data sets.

\section{Methodology and results}

The applied methodology of the study as well as the continuative approaches for grassland mapping and the achieved results are discussed in this section.

(1) Classification of intensively used grassland areas (Fig. 4)

The main objective of this part of the study is to check the suitability of remote sensing data for detailed grassland classification. In this way, the biotope mapping activity can exclude the intensively used grassland in their fieldwork campaign, to save time and money.

While the distinction of tree-covered biotopes is rather easily done by aerial photographic interpretation, extensive grassland cannot easily be separated from intensive grassland or in some cases even from arable fields. Thus, the primary idea was to exclude intensively used grassland automatically by an automated analysis of satellite images.

The first step of the classification process was a data homogenization, which means that the provided data sets (LANDSAT, orthophotographs, DEM and vector GIS files) had different projection types and the ASTER data has to be orthorectified by image processing software (Leica Photogrammetric Suite). A mosaic for the huge number of orthophotographs (a single ortho-photograph covers $1.25 \mathrm{~km}^{2}$ ) has been processed and the original resolution of $25 \mathrm{~cm}$ was degraded down to $50 \mathrm{~cm}$, to reduce data amount. To minimize the size of datasets for image processing, the whole extensive image datasets are cut to the three district limits.

Normalized Difference Vegetation Index (NDVI), the ratio of the difference of near-infrared and red reflectance to the sum of these two variables, is the dominant spectral vegetation indicator of grassland biophysical measurements. NDVI tends to enhance the vegetation signal, reducing the atmospheric and edaphic influence, and standardizing the spectral data. This is particularly true when vegetation shows vigorous photosynthetic activity. Therefore, it has been used in this study to divide intensive (cut and well growing, high greenness) grassland from extensive (slower blooming and growing, mainly dry and brown) grassland (Fig. 3). Depending on the climatic situation the vegetation period of intensive grassland starts between the end of March (south-eastern lower part) until April (mountainous areas). With a multi-temporal change detection approach (March to July) it is possible to verify the different growing intensity in the whole investigation area (Fig. 5).

The Digital Elevation Model (DEM) with a resolution of $10 \mathrm{~m}$ is used to make a rough slope classification of the area. Slopes with more than $20^{\circ}$ will be excluded due to the precau- 


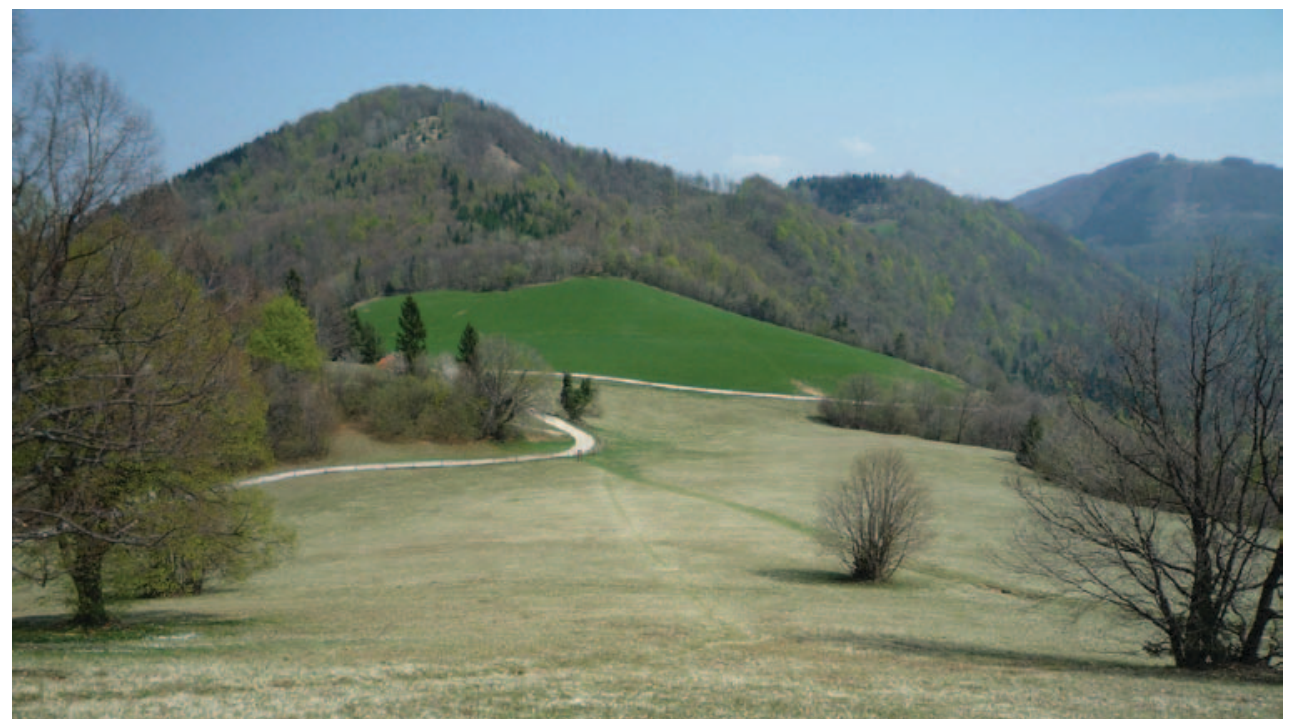

Fig. 3. Difference between extensive and intensive used grassland in the mountainous areas (Photo W. Sulzer).

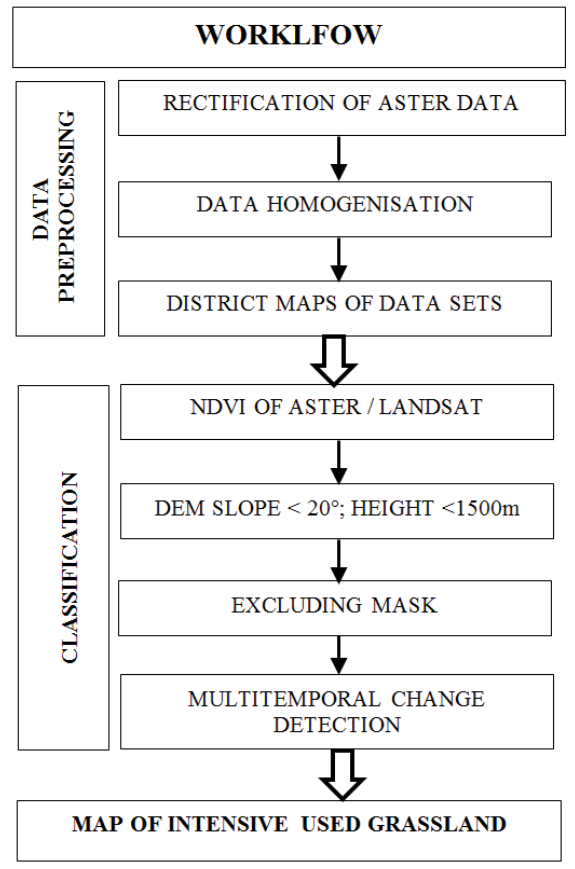

Fig. 4. Flowchart of grassland classification tion that an intensive treatment by machines (tractors) or scythes is not possible on steeper slopes. So the probability to find intensive grassland in steeper slopes is lower than in gentle slopes. Additionally, the maximum height of the potential investigation area was set by $1500 \mathrm{~m}$ asl.

In the 'excluding mask' large areas which are not assigned to open land are defined to reduce the potential grassland yields. The vector data set from the GIS Steiermark/Styria (www.gis.steiermark.at/) includes arable land, settlement areas, rivers and lakes and forests.

(2) Preparing orthophotograph-based landuse polygons for the field mapping

The second application is an object-based approach, which produces polygons of different biotope and land-use types. The aim is to generate an initial image map to assist fieldwork for a biotope mapping. Fig. 6 shows an example of base map for fieldwork, where the investigator can easily adapt digitally by means 

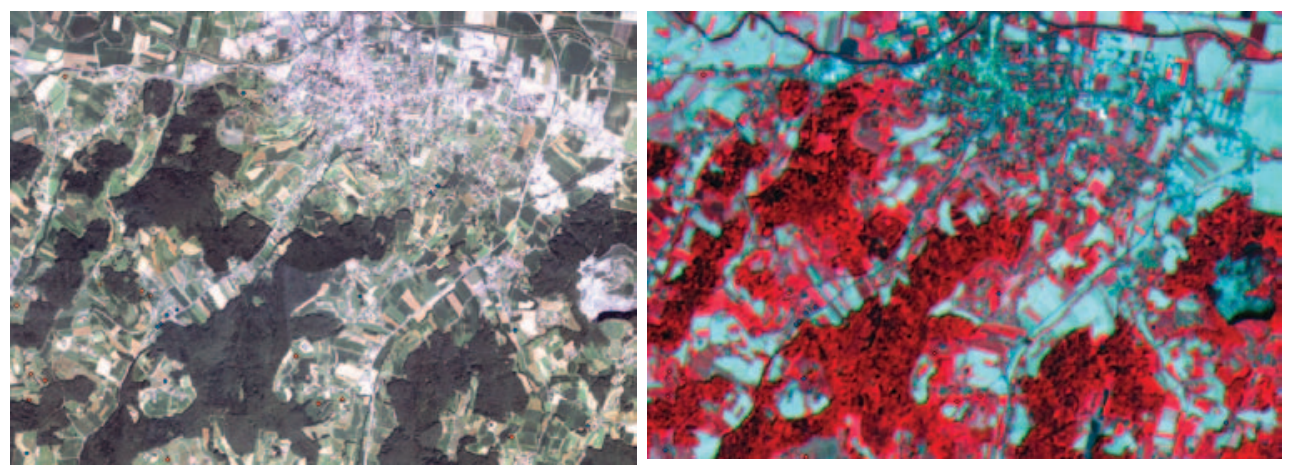

Fig. 5. Orthophotograph (left) and ASTER image (right) with intensively used grassland yields (dots).

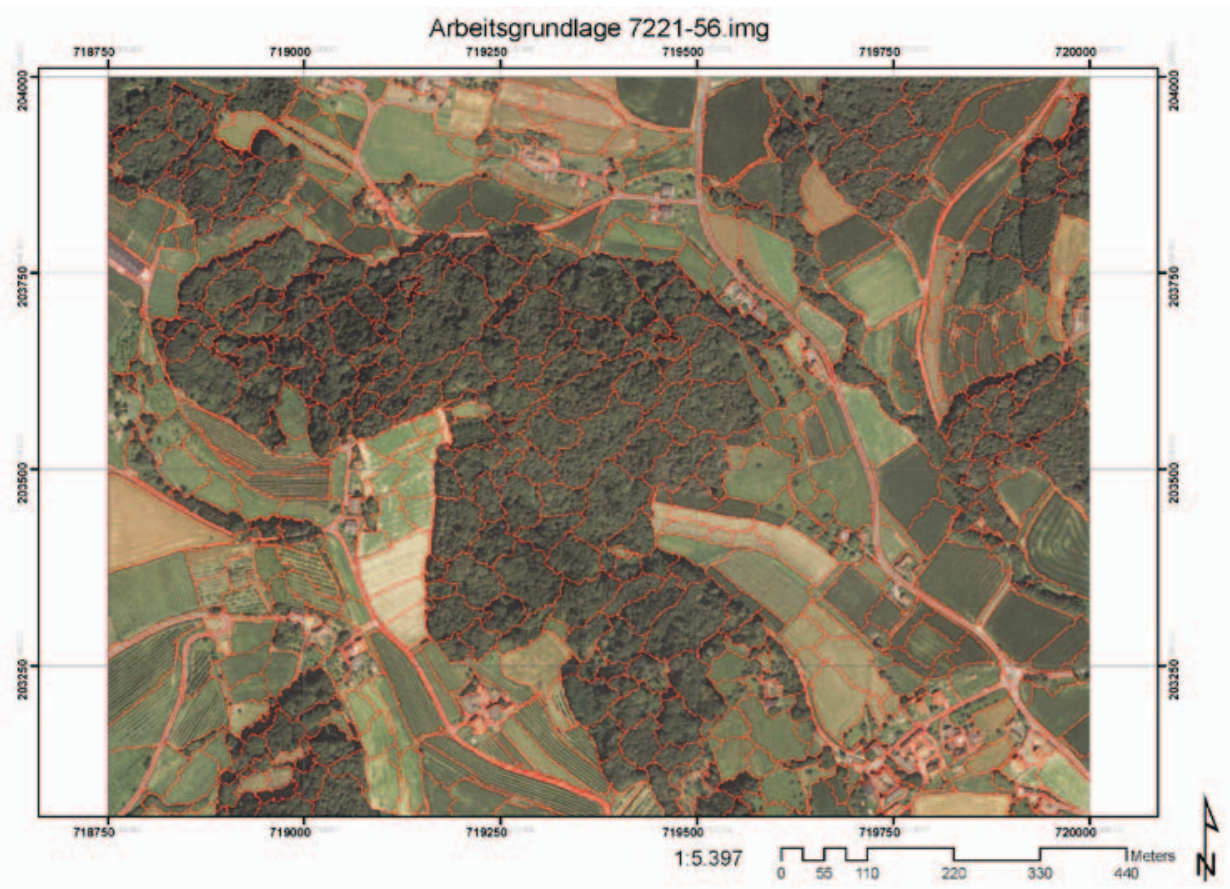

Fig. 6. Object-based segmentation for fieldwork base maps.

of a field laptop the shape of the polygons and set attributes for the land cover types. Conventional digital RGB orthophotographs were processed for different levels of segmentation.

\section{(3) Designing a mobile GIS-based mapping infrastructure (Fig. 7)}

As already mentioned, grasslands can be seen as pseudo-stable environments which are more or less reconfigured by natural or man-made, periodical or a-periodical disturbances. These influences usually induce processes which lead to metamorphoses of the structure of the 


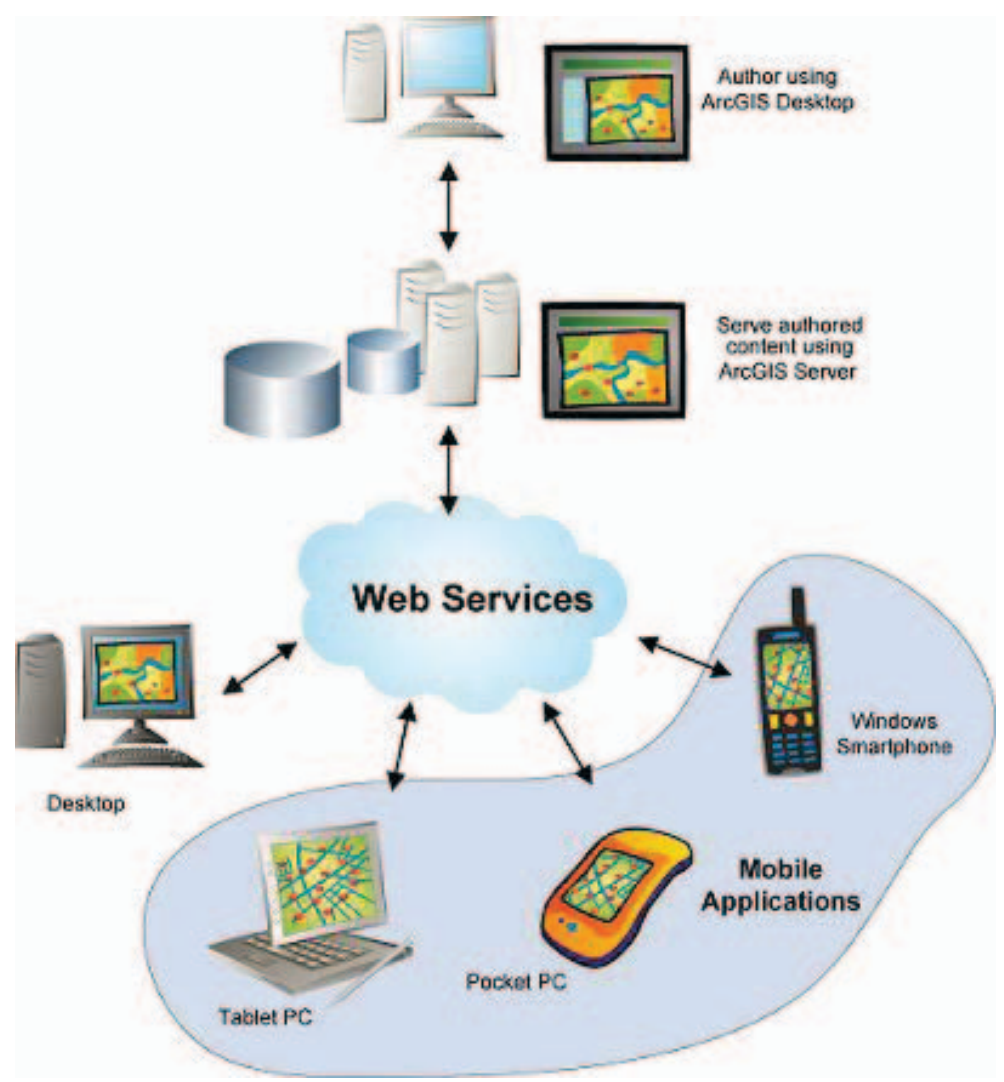

Fig. 7. Client/server architecture of a web-based geodata management and monitoring system (www.mapping.com/ mobileanwendungen).

grasslands themselves as well as of the environment (e.g. chemical composition and texture of soils, soil moisture; Knauer, 1979; Schreiber et al., 1997). These phenomena give reasons for a specific profile of tasks which GIS specialists in grassland mapping scenarios have to deal with:

- $\quad$ The intensive use of digital data management and storage infrastructure (Geodatabase)

- The importance of the locational component in the data which typically enables the application of powerful GIS toolsets for multi-dimensional analysis of spatially enriched data model typically generated by 'vector producing' acquisition hardware (in most cases GNSS)

- The need to acquire, verify, analyse and visualize spatially referenced data and to compare it with reality; the last work package particularly is typically handled during cost-intensive field campaigns by means of highly mobile (handheld) equipment (which implies a fieldwork preparation as far as possible)

- The need to expand the spatial data model by addition of time to a spatio-temporal data model which allows the derivation of models and the development of predictions.

These topics necessarily lead to a catalogue of technological requirements covering hardware 
(Pocket PC, Tablet PC, Smartphone; Android-, IOS- or Windows-driven with integrated or external GPS), software (mobile GIS/GPS solutions like ArcPad or others), wireless communication infrastructure (Wi-Fi, cellular phone signals, Bluetooth) and programming tools (Java, VB, Python, $\mathrm{C}++)$. These elements facilitate a system architecture which is very similar to that of a web-based GIS consisting of client-side and server-side components. The former are end-user hardware/software platforms providing data/map edition, visualization and analytical operations as well as sending user requests and the transmission of information updates. Furthermore, GIS-enabled clients implement the positional data acquisition, regardless of external or internal GPS-units. The latter provide comprehensive (multi-server) geospatial data management, perform more complex GIS analyses and are responsible for the handling of user requests and user management. At last, the linkage between mobile units and GIS content and service units is established by a two-way wireless communication component enabling data synchronization by bridging the gap between server-side and client-side. Concerning different aspects of weakness of mobile hardware systems distributed databases are often called 'small-footprint databases', referring to the fact that - although they were installed on a mobile client - they save the collected data persistent and in a highly structured way. Thus, in the given context, for example, an almost fully featured geodatabase representing the locational factors for characterization of grasslands should also contain parameters like climate (radiation, temperature, humidity, precipitation, snow cover, wind), relief (height, landform, slope, aspect), soil (soil temperature, humidity ratio, acidity, soil profile, grain size) and biotic factors (micro-organisms, soil animals, herbivores). Additionally, these variables/attributes have to be documented by photographs and standardized metadata sets. According to the performance of data acquisition units, databases have to be adapted to meet these special requirements and needs. Although the physical constraints are present, the goal of the mobile database should be to provide most of the functions of a 'regular' database. Therefore, they are rarely designed as a stand-alone product, but provide a more or less simplified subset (front end) of the complete DBMS; in this client/server configuration mobile terminals request the data (as feature service) or maps (as map service) from a ready-to-use, predefined central database (Derekenaris et al. 2001). This procedure allows the time-consuming database design in the more comfortable office/lab environment and at once assures a maximum of usability and performance during the fieldwork (ESRI, 2012 a,b and c). During the workflow, a replica of the relevant subset of the geodatabase is sent to the device, which establishes a local working dataset without any further server access; by means of synchronization, the updated or newly collected dataset is sent back to the master database. Continuously increasing computer performance and storage capacity as well as the rapidly growing 'overall smartness' of the mobile devices (more functionality and usability of mobile database models) will achieve a cost-effective and highly usable solution for environmental monitoring and management tasks.

\section{Conclusion}

This study reveals the suitability of remote sensing data for detailed classification and monitoring of biotopes, especially grasslands. However, since the mapping guideline of the client of the project, the Styrian government, did not allow an automated exclusion of areas such as arable fields or intensified grassland, the excluding mask provided by the Institute of Geography must not be used. Furthermore, the intensively and extensively used biotope categories distinguished 
by the mapping guideline are often very similar to each other. The field check of the excluding mask resulted in a $60 \%$ hit ratio due to the floristically orientated mapping guideline, but a significantly higher hit ratio due to the level of intensity of agricultural treatment. Thus, the excluding mask was used not to partly substitute the fieldwork but the information was provided to the biotope mapper as an additional information, depicted as a yellow point for intensive farmland in the polygon. Furthermore, the verification of the classification made by the biotope mapper was focused on extreme differences between the respective assessments of the given polygon, to the classification as 'excluded' by the remote sensing project.

\section{Acknowledgements}

The authors thank Dr. Hugo Kofler (Ziviletchnikkanzlei (http://www.kofler.at) ) for his interest to implement new technologies in his biotope mapping activities and providing us together with GIS Steiermark (www.gis.steiermark.at/) and FA 13C (Fachstelle Naturschutz, http://www.verwaltung.steiermark.at/) the databases.

\section{References}

Amt der Steiermärkischen Landesregierung (2008). Biotoptypen - Katalog der Steiermark. Amt der Steiermärkischen Landesregierung Fachabteilung 13C Naturschutz.

Angold, P.G., Gurnell, A.M. \& Edwards P.J. (1996). Locational errors in maps from environmental surveys and their implications for information extraction. J.Environ. Manag., 47, 341-354.

Bock, M. (2003). Remote sensing and GIS-based techniques for the classification and monitoring of biotopes. J. Nat. Conserv., 11, 145-155. http://www.urbanfischer.de/journals/jnc

Bock, M., Xogis, P. Mitchley, J., Rossner, G. \& Wissen M. (2005). Object-oriented methods for habitat mapping at multiple scales - Case studies from Northern Germany and Wye Downs, UK. J. Nat. Conserv., 13, 75-89. DOI: 10.1016/j. jnc.2004.12.002.

Derekenaris, G., Garofalakis, J., Makris, C., Prentzas, J., Sioutas, S. \& Tsakalidis A. (2001). Integrating GIS, GPS and GSM technologies for the effective management of ambulances. Computers, Environment and Urban Systems, 25, $267-278$.

Ehlers, M. (2000). Integrated GIS-from data integration to integrated analysis. Surveying World, 9, 30-33.

Ehlers, M., Gähler, M. \& Janowsky R. (2003). Automated analysis of ultra high resolution remote sensing data for biotope type mapping: new possibilities and challenges. ISPRS Journal of Photogrammetry \& Remote Sensing, 57, 315-326. DOI: 10.1016/S0924-2716(02)00161-2.

ESRI (2012a). ArcPad 10 Help-What ist he ArcPad Extension for ArcGIS Server?, http://help.arcgis.com/en/arcpad/10.0/ help/index.html\#/What_is_the_ArcPad_Extension_for_ArcGIS_Server/00s10000001w000000/, last visited 09-2012

ESRI (2012b). ArcPad 10 Help-Authoring Data for ArcGIS Server, http://help.arcgis.com/en/ arcpad/10.0/help/index. html\#/Authoring_Data_for_ArcGIS_Server/00s10000003r000000/, last visited 09-2012

ESRI (2012c). ArcPad 10 Help-Publishing Data to ArcGIS Server, http://help.arcgis.com/en/ arcpad/10.0/help/index. html\#/Publishing_Data_to_ArcGIS_Server/00s100000058000000/, last visited 09-2012

Franke, J., Keuck, V. \& Siegert F. (2012). Assessment of grassland use intensity by remote sensing to support conservation schemes. J. Nat. Conserv., 125-134. DOI: 10.1016/j.jnc.2012.02.001.

Knauer, N. (1979): Wiederherstellung naturnaher Grünlandpflanzengesellschaften durch landwirtschaftliche Nutzung. Ber. Internat. Fachtagung Pflanzensoz. Land- und Almwirtschaft Gumpenstein, pp. 127-136.

Poulton, C.E. (1985). Evolution of remote sensing in range management, speculations on its future. Proceeding of Pecora 10 remote sensing in forest and range resources (pp. 2-17). Fort Collins, Colorado.

Schreiber, K-F., Broll, G. \& Brauckmann H.-J. (1997). Vegetationskundliche, bodenökologische und faunistische Untersuchungen auf den Bracheversuchsflächen von Baden-Württemberg - eine Bilanz nach über 20 Versuchsjahren. Veröff. PAÖ, 22, 49-68.

Weiers, St., Bock, M., Wissen, M. \& Rossner G. (2004). Mapping and indicator approaches for the assessment of habitats at different scales using remote sensing and GIS methods. Landsc. Urban Plann., 67, 43-65. DOI: 10.1016/S01692046(03)00028-8. 